\title{
FIELD ADMINISTRATION IN OPS $\dagger$
}

\author{
ANNE P. FloRY*
}

For the average price regulation issued by OPS, the progress of administration after issuance may be described through five phases: public (including trade) relations; processing of individual actions; ascertaining defects and making corrections through amendments; evaluating compliance; and identifying and punishing individual violators. These phases were not necessarily followed in strict sequence, and many of them went on simultaneously. But they were interrelated, and the skill of a regional director and his staff in directing the energies of the field force toward each of these phases, as conditions required, determined the success or failure of a well-rounded regulatory program. In viewing the administrative problem from this angle, it becomes clear that, apart from work entailed in developing area price regulations, and in processing some types of individual price actions, activities of the field were devoted to securing compliance with the regulations or to developing a favorable climate for compliance.

All of the activity phases in the field were cooperative ventures. A particular "component"-i.e., a major field organizational unit, counterpart to an office, such as Price Operations, Enforcement, or Office of the Chief Counsel, at the national level-might play a dominant role or a supporting role, depending on the nature of the compliance problem in the area under the jurisdiction of the office. With respect to some regulations, a given field office would have no interest at all. Interest would be most acute where there was full responsibility for issuing pricing orders, either area or individual, or for processing some type of price action. Intensity of interest ranged between these points, depending on the type of regulation, the number of establishments affected, availability within the office of specialized knowledge on the regulated commodity, economic pressures, attitudes of the industry, and sheer ingenuity of the people in the office in treating the problems which arose.

\section{Public Relations}

The public relations job in OPS was many sided. It did not stop with the mere dispatch of a press release announcing the issuance of a new regulation or amendment. It involved getting information to the person to be regulated, answer-

†This article is adapted from a longer study, entitled Field Administration of Price Stabilization, published in June, 1953, in the series of OPS History Monographs by the Office of Price Stabilization. The opinions expressed herein are the author's and do not necessarily reflect those of any past or present Government agency.

* A.B., Longwood College, Farmville, Va.; A.M. in Political Science, Duke University. Formerly employed in the field establishment and the departmental service of OPA, in both program and management capacities. Former Chief of the Program and Reports Branch, Office of Price Operations, OPS. Currently employed by the Post Office Department as a consultant on salary administration. 
ing his inquiries or requests for interpretation, avoiding unnecessary delay in processing his request for adjustment, conditioning his attitude toward voluntary compliance, and providing assurance that he would not be put to a disadvantage by the noncompliance of his competitor or supplier. It involved courteous treatment when he visited the office or was visited at his place of business by a price specialist, accountant or investigator. And it further involved his confidence that price control was being administered with competence and evenhandedness. Hardest of all was the task of convincing him that price control was an emergency measure undertaken in the public and, therefore, in his best interest.

It is rather difficult to say where the main burden fell. Generally, it was asassumed that the director of the office and his information officer carried the main share for general dissemination of news about regulations and office activities. Price specialists, presumably, were hired to deal with businessmen, to talk their language in explaining regulations, and to identify weaknesses in the regulations or other impediments to trade acceptance and cooperation. But public relations problems were broader than any demarcation laid down in a prescription of functions. While it is impossible to describe all facets, some of the more important problems and devices for dealing with them are discussed below.

\section{A. Distribution of Regulations and Other Materials}

OPS from the beginning assumed responsibility for getting copies of regulations to affected business establishments. The mechanics for doing this were, of course, nonexistent at the time GCPR (General Ceiling Price Regulation, I6 FEd. REg. 808 (I95r)) was issued, and in order to get as widespread distribution as possible of the initial printing of over 2,900,000 copies, the aid of chambers of commerce, banks, local trade associations, and volunteer groups was solicited wherever possible. As a matter of fact, OPS depended on this kind of makeshift distribution for several months during which many of the regulations affecting the largest segments of the business population were issued. With the issuance of CPR 22 (Manufacturers' General Ceiling Price Regulation, I6 FED. REG. 3562 (I95I)), OPS used direct mail against an established list for perhaps the first time. Several regional offices, particularly those with former "OPA'ers" in administrative positions, began developing direct mail lists as one prerequisite for a planned program of distribution. Direct mail as the prime method of distribution was adopted by OPS in the spring of 1951, when field offices were instructed to begin preparation of lists covering wholesalers and retailers coded as to principal type of business. All likely sources were used-tax lists, local license lists, telephone books, and state and city directories and, of course, reports and filings submitted to OPS. The agency was handicapped in this project since no general business registration was undertaken, but the lists were subject to constant revision and toward the end of the program they probably comprised a valuable compilation.

The problem of distribution was further complicated by the issuance, not always simultaneously, of public forms and trade guides or bulletins to accompany the regulation. When these supporting documents were released separately, the dis- 
tribution process had to be duplicated, and the agency had to bear the disgruntled complaints of businessmen, clamoring for necessary public forms. The best synchronization of releases was achieved with respect to CPR 93 (Construction Services, I6 Fed. REg. Ir592 (I95I)); CPR I34 (Restaurants, I7 FED. REg. 2750 (I952)); Amendment 8 to CPR I34 (I7 FEd. Reg. Ir597 (1952)); and Amendment 4 to CPR 34 (Services, I7 Fed. REg. 9602 (1952)). Each of these involved multiple documents. Release of CPR 83 (New Passenger Cars, I6 Fed. Reg. 10594 (1951)) and of CPR 16x (New Consumer Durable Goods, 17 Fed. Reg. 6842 (1952)) without the public forms, which followed weeks after the issuance of the regulation, were the most aggravated cases of bad timing. Needless to say, the field was merciless in its constant and justifiable criticism of the failure of the national office to establish and enforce better procedures for insuring simultaneous release of a regulation and all necessary supporting materials.

\section{B. Meeting the Trade}

A major impediment to the development of an effective trade relations program in OPS was the lack of sufficient staff to take full advantage of the opportunities presented early in the program when many important regulations were issued. As of the end of April x95x, the total price staff in the field numbered 1,078; of these, only 733 were in district offices. One month later, the numbers had been increased to a total of 1,745 with 1,276 in the district offices. By October, the total price staff numbered 3,190, of whom 2,573 were in district offices. Thus, the field met its peak trade relations load when the district offices were less than half-staffed. This was a fact which probably had considerable bearing on trade attitudes toward OPS and its regulations. Through a series of deadline extensions, the agency confessed to its inadequacy, both to deal with reports that business establishments were required to file and to carry the story of regulatory requirements to the trade.

One of the most tangible evidences of compliance among retail establishments was the amount of response to base period filing requirements. If the response was great before the effective date of a regulation, the main emphasis in subsequent dealings with the trade was on adherence to pricing rules. If response was slow, then the price agency was confronted with a compliance situation that was very hard to handle, for the nonfiler presented a prima facie case of non-compliance, even before it was determined whether his prices were, in fact, at or below his ceilings. In some instances, as under CPR 7, preparation and filing of a base period chart was required before any prices could be legally charged. A big question arose, then, as to when persuasion was appropriate and when recourse should be had to enforcement. OPS had to face this question, with respect to most retail regulations, in the summer of 195I, at a time when it was, unfortunately, operating under a temporary extension. In general, it may be said that there was only one practical answer: the volume of non-filers made case-by-case enforcement out of the question; price specialists and other field personnel had to use all available means to obtain initial compliance, and the willful violators were left to Enforcement. 
Many regions seem to have hit upon the price clinic as a compliance device, at about the same time. In the Boston Region, clinics were organized around July I, I95 and they continued to the end of the year. Some of the districts in the Atlanta Region found their Mayor's Committees helpful in setting up and organizing trade meetings or clinics. In the Dallas Region, the trade relations program was organized around trade clinics, trade meetings, group appearances, and informal trade contacts. For that region, the price clinic activity was described as, "One or more Price Specialists stationed at designated points on regularly scheduled dates for the purpose of consulting with representatives of trade and industry and assisting them in their problems." 1 Each clinic was carefully scheduled and manned, and regular reports on activity were required. In the Cleveland Region, there was the Toledo Plan, and in the Denver Region, the Salt Lake City Plan, both devoted to systematic contact. Variations of these plans, some well organized and continuous, some more or less sporadic, could be found in practically every region or district. Concrete evidence of the success of organized approach may be found in the record of the Toledo Office: ${ }^{2}$

The Clinic Plan has had direct effects upon the Enforcement Program in the Toledo District. Prior to the concentrated efforts of the Price Operations Branch to secure filings under CPR 34, very little success had been experienced by the Enforcement Branch in their investigations of non-filers under CPR 34. Those investigations which were undertaken usually resulted in the seller being informed of the filing requirement, obtaining the filing, and the dismissal of the investigation, since in most cases no violations were disclosed other than the failure to file. After the Price Operations Branch had invited some I,500 non-filers to attend Clinics, and upon the attendance of more than 50 per cent of those invited, filings were received at a very high rate. Of the original 1,500 cases, it was necessary to refer only 40 to the Enforcement Branch for investigation because of non-filing. Similarly, under CPR 83 , it was necessary to refer only seven cases to Enforcement for reason of failure to execute the required Form 98 .

There was, of course, virtually no limit to the amount of effort and staff time that could be put into programs which required continuous contact in order to acquaint businessmen with the many requirements of regulations. Price and Enforcement, as well as Legal and Public Information, had an interest and a stake in such programs. Too often in OPS these interests were not identified. Enforcement people were apt to feel that Price had, despite its trade relations activity, left a vacuum which could be filled only by intensive investigative work, undertaken primarily to prevent violations and secure voluntary compliance and only secondarily to obtain conviction. Price people were apt to feel that Enforcement was too zealous in hunting out the unwary, and not zealous enough in dealing with the real villains.

\footnotetext{
${ }^{1}$ Regional Price Instruction No. 4-25, Rev. 2, Dec. 30, 1952, issued by the Dallas Regional Price Executive.

2 Toledo Clinic Plan of Trade Assistance Program, Cleveland Regional Office (undated, but probably issued in the spring of 1952). This document is complete with procedures and exhibits.
} 


\section{INTERPRETATIONS}

The question as to what was an interpretation derived its importance from the fact that a businessman sending an inquiry into the agency could receive an answer from any of several places, depending entirely on the nature of the inquiry. If he were aware of the procedural requirements of the agency, he might specifically request an official interpretation, so that he would have a reply from the Chief Counsel, or one of his numerous designees in the national office or in the field. ${ }^{3}$ But more likely, he would simply state his problem and leave it to the agency to determine whether the answer required "an authoritative statement of the meaning of a regulation, order or allocation ... as applied to a specific set of facts." Since most of the incoming mail of the agency was distributed according to the commodity involved, letters landed initially on the desks of price specialists. This was the problem, as seen by one Regional Director: ${ }^{5}$

... the placing of the business analyst as the recognized representative of the agency with the business community presented many difficulties, in that the line between presenting explanations to businessmen and making authoritative interpretations is exceedingly fine. Those analysts recruited from responsible business positions were used to working with attorneys and recognized the necessity of consulting with and being closely guided by legal advice. The difficulties arose with those analysts who had little business experience and were resentful of the attorney's authority and were loath to consult with him.

The problem also worked in reverse. It was suggested by field spokesmen that interpretations could have been improved through consultation, in advance of issuance, with price specialists familiar with an industry and with its peculiar trade practices and terms. This approach was recognized in the first procedure issued by the agency on interpretations, but was abandoned, for reasons unknown, in later revisions.

Delays encountered in the issuance of interpretations, a constant administrative worry, arose from three causes: (I) workload; (2) referral to the national office because of limitations on delegations; (3) inexperience of field counsel, particularly district counsel.

Workloads of attorneys varied from region to region, not altogether in proportion to measurable items coming into the office in the form of letters, interviews, and requests for price action. An additional factor was the internal procedure followed by the particular field office with respect to the utilization of attorney personnel. Those offices, as in the New York Region, for example, where there was a tendency to use attorneys extensively as a check and balance on all trade relations and price action work, offered a contrast to offices like those in the Dallas Region where at-

${ }^{3}$ Price Procedural Regulation I, I6 FED. REg. 4974 (195I). This document made it clear that anything signed by anybody other than the Chief Counsel or his designee was not an official interpretation.

'Definition of an official interpretation as given in Interpretations: Authority and Procedures for Issuance, OPS MaNUal, Pt. 5, c. 4 .

${ }^{5}$ Letter, E. R. Thissen, Acting Regional Director, to Joseph H. Freehill, Mar. 13, 1953. 
torneys were consulted only when their advice was felt to be needed. Ratio of staff in the Counsel's office to Price personnel ranged all the way from $x$ to $4 \frac{1}{2}$ in New York to $I$ to 7 in Kansas City and San Francisco.

Regional and district counsel were given authority, initially, to issue interpretations on problems within the spirit and scope of precedents established by the national office, on new or novel problems involving purely local situations, and in other cases of extreme urgency after telephonic clearance with the national office. These instructions, which were published in the OPS Manual, imposed seemingly severe limitations upon the authority of regional and district counsel to issue official interpretations without prior clearance with the national office. These restrictions appeared reasonable and necessary in the early days of OPS, when the field office legal staffs were not fully recruited or trained. As time went on, however, these precise instructions were not literally followed by the regional and district counsel, who instead adopted a common sense approach in determining when they could safely issue an official interpretation without prior national office clearance, even in the absence of a national office precedent. The liberalness with which the regional and district counsel construed these instructions, of course, varied according to the temperament of the field office personnel involved. In June I952, the Chief Counsel bowed to growing pressure from field offices and issued new instructions actually putting in writing the more liberal procedure which many regional and district counsel had been following for some time.

In spite of all efforts to expedite national office release, delays were not infrequent. For example, the Minneapolis Regional Price Executive, directing his comments to the Industrial Materials and Manufactured Goods Division, stated in a progress report (period ending March 27, 1952):

Unfavorable comment is still being directed to this office because of the long period of time necessary in getting interpretations from the national office in answer to our regional inquiries of questions originating at the district level. It is still found that many of these interpretations are received after a waiting period of from one to three months which puts the supervisory office in a very embarrassing position. We suggest this be given some consideration.

In an effort to meet the complaints made from the field about national office delay in answering field requests for interpretations, the Chief Counsel set up an elaborate control system for regional counsel interpretative inquiries in the Field Operations Division of the Office of Chief Counsel. However, in spite of periodic exhortations from the Chief Counsel to his staff in the national office, the plan never achieved the results desired. The basic problem was that as long as the agency was operating on a completely active basis, the commodity division attorneys in the national office were swamped with competing priority demands which included the preparation of new regulations and amendments, processing of adjustments and other individual price actions, and other functions, all of which were marked "urgent." A really substantial improvement in the expeditious handling of regional 
counsel interpretative inquires was achieved only in the later stages of the agency when active controls were reduced to an extent which gave commodity division counsel more time to devote to interpretative problems alone.

Inexperience was primarily exhibited in requests for pre-audits, which some regions attempted to forestall through extensive circulation of locally issued interpretations. One region considered reluctance on the part of counsel as the prime cause for delay: ${ }^{6}$

The function of interpreting regulations, while well-conceived, was not always well carried out in practice. Some, but not all, of the District Counsel were somewhat timid about exercising the discretion entrusted to them. On occasion, when questions came up regarding interpretations, so much time was lost in getting the right answer that the need for the answer had passed by the time the decision was made.

It was recognized in the national office that it was of the utmost importance that interpretative positions taken by the national office should be made known quickly in some usable form to all field offices. A program to this end was inaugurated on a small and informal scale with the issuance of the National Interpretation Series in the summer of 1951. This program, which was operated by the Coordination of Interpretations Division, involved the periodic release in mimeographed form of digests of important interpretations issued in the national office. Early in 1952 the program was expanded and placed on a much more professional scale with the publication in the OPS Looseleaf Service, following each Ceiling Price Regulation, of the useful and important interpretations issued under that regulation. If such a publication program had been inaugurated in the early days of OPS and operated on a larger scale, it would have been of inestimable value to attorneys in the field offices in connection with their interpretative functions. However, as in the case of many other OPS problems, the pressures of impossible workloads and inadequate personnel prevented the publication program from reaching the scale which would have been most helpful until the later stages of the agency, when it no longer had any substantial value except for historical purposes.

\section{III}

\section{Processing Individuad Price Actions}

Most of the directed effort of the field fell in the area of processing price actions. Direction was both general, by way of organizational arrangement, functional assignments, and procedural definition, and specific through delegations of authority, operating instructions for particular price action provisions, and field contact of commodity divisions in the national office.

It is rather difficult to isolate general operating problems arising in connection with this aspect of field work. The difficulties about which field offices complained were so varied as to prompt the conclusion, by and large, that either they sprang from individual personnel situations in field offices, or they were concomitants of faulty treatment by the national office of particular regulatory problems. A corollary

'Ietter, M. A. Brooks to Joseph H. Freehill, Mar. I8, I953. 
of this conclusion is that the national office probably met its general responsibilities in this area with a reasonable degree of success.

\section{A. Price Filings ${ }^{7}$}

During the course of its operations, OPS processed over 3,000,000 separate price reports submitted under the filing requirements of its various regulations. Most of these reports were in the nature of base period filings, and over nine-tenths of them were filed with district offices. The chart below will show the trend of workload from this source.

Nearly two-thirds of the total number received were filed with OPS within its first six months of operation. The overwhelming impact of this volume at a time when field offices were being organized and staffed probably accounted for the carelessness in handling this particular type of price action which prevailed throughout the first year.

While instructions differed from regulation to regulation, there was generally the requirement that each report should be reviewed for completeness and accuracy. In addition to the initial problem of getting business establishments, particularly small ones, to file, there was the problem of securing corrected reports. Some indication of the magnitude of work involved in following up in this respect is revealed by the examples given in the following table, which shows the work status in this area as of the close of the field program in February, I953.

\begin{tabular}{|c|c|c|c|c|c|}
\hline $\begin{array}{c}\text { Total } \\
\text { Received }\end{array}$ & $\begin{array}{c}\text { Total } \\
\text { Reviewed }\end{array}$ & $\begin{array}{l}\text { Initially } \\
\text { Accepted }\end{array}$ & $\begin{array}{c}\text { Not } \\
\text { Acceptable }\end{array}$ & $\begin{array}{l}\text { Corrected } \\
\text { by Filer }\end{array}$ & $\begin{array}{l}\text { Outstanding } \\
\text { for Correction }\end{array}$ \\
\hline $\begin{array}{l}\text { CPR } 7 \\
\text { (Consumer Goods) } \cdots 3 \text { I } \cdots, 283 \\
\text { CPR II }\end{array}$ & 308,902 & 203,275 & 105,627 & 89,662 & 15,965 \\
\hline (Restaurants) $\quad \ldots \cdots \cdots 370,154$ & $366,25^{\circ}$ & 286,721 & 79,529 & $5^{1,994}$ & 27,535 \\
\hline $\begin{array}{l}\text { CPR } 34 \\
\text { (Services) } \ldots \ldots\end{array}$ & 748,663 & 594,590 & 154,073 & 120,255 & $33,8 \mathrm{I} 8$ \\
\hline $\begin{array}{l}\text { CPR } 93 \\
\text { (Construction Services) } 39,545 \\
\text { CPR } 134\end{array}$ & 38,9 I0 & $3^{1,045}$ & 7,865 & 5,328 & 2,537 \\
\hline 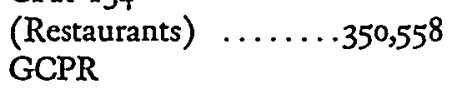 & 343,705 & 288,922 & $54,7^{83}$ & 31,047 & 23,736 \\
\hline arity Adjustments) $.24,763$ & $23, \mathrm{r} 77$ & $r 9,496$ & $3,68 \mathrm{I}$ & $2,4 \mathrm{r} 4$ & $\mathrm{I}, 267$ \\
\hline iscellaneous $\quad \ldots \ldots 996,246$ & 952,292 & 888,309 & 63,983 & 57,342 & $6,64 \mathrm{I}$ \\
\hline eld Office Total & $, 781,899$ & $3^{12,35^{8}}$ & 469,541 & $\overline{35^{8}, 042}$ & 11,499 \\
\hline
\end{tabular}

Most of the work on price filings was done by commodity specialists or under their direction. Extensive utilization of highly paid commodity specialists on this type of work was probably wasteful. The ratio of clerical staff to specialist staff should have been more nearly one-for-one than was provided in original staffing pat-

${ }^{7}$ Definition as given in OPS Manuas Pt. 4, c. $2, \$ 6.3$, was as follows:

". . a report of a base period or current ceiling price, pricing method, or transaction filed with OPS, which constitutes notice to OPS, as required by a regulation, but which does not require written approval by OPS, or the expiration of a time limit before effectuation, even though it may later be disapproved or revised by letter order, or corrected or amended by the seller." 
terns or than was probably achieved in most offices. Failure to standardize the tremendous amount of administrative detail required in handling price filings and in establishing and maintaining appropriate records was an operational shortcoming, contributing to unevenness and confusion in processing.

Some of the filing provisions, especially those not pertaining to base period reports, entailed processing of a very complicated nature. Most prominent examples of this type were the parity adjustments reports filed under GCPR. In order to obtain the kind of careful analysis and review required, many field offices assimilated these to "docket" actions and passed them through the procedure described below.

\section{B. Docket Actions}

For purposes of administrative control, OPS required that applications for the establishment of prices and applications for price adjustments be assigned individual docket numbers and that a full processing record be maintained. Monthly reports on receipts and dispositions were required, by type of action and by regulatory provision, from all processing offices. ${ }^{8}$

It was not until August I95I that OPS issued a standard procedure for processing adjustment actions in field offices. An attempt was made at that time to define the responsibilities of the various officers from the several components participating in adjustments, as follows:

. . the commodity specialist shall furnish all relevant data and analysis, the commodity branch economist shall assemble all the data and prepare the economic brief, the commodity branch attorney shall examine the economic brief for its legal adequacy, the chief economist shall review and approve the brief, the price executive shall examine the file for consistency with price policy, the office counsel shall examine the file for legal clearance and issue the letter-order, the chief economist shall examine the letter-order to ascertain whether it incorporates the substance and purpose of the economic brief, and the director shall sign the letter-order for issuance to the applicant.

By this time, field offices had, in most cases, installed their own procedures and had made organizational arrangements to suit these practices. Some offices, for example, did not assign economists to commodity branches, while still others had placed full responsibility for adjustments on their economic staffs. Reliance on the commodity staff for analyzing requests and finding the facts was a decided shift from OPA procedure, undertaken by OPS to make sure that the adjustment process

${ }^{8}$ Actions were administratively classified by type as follows:

I. Adjustment-An increase in an established ceiling price or a revision in an established margin or ratio, for an individual seller or group of sellers, based on an application filed in accordance with and under conditions specified in a regulation and subject to approval, either actual or constructive, on the basis of prescribed criteria.

2. Authorization-A ceiling price or pricing method established by order of OPS in response to an application submitted by a seller in accordance with provisions of and under conditions specified in a regulation.

3. Determination with a Time Limit-A determination of a ceiling price or pricing method (not an increase or a revision of one already established) filed by a seller with OPS, which may be used after a specified time unless OPS takes written action to modify or disapprove the ceiling price or requests additional information. 
was not wholly dominated by the economist's views. The shift made necessary a complicated clearance process.

It was found, in actual practice, that few commodity specialists were equipped to undertake the detailed analysis required and that they approached conclusions intuitively from business experience and knowledge of the applicant's operations rather than from meticulous sifting of facts. Most damaging of all, from a public relations angle, was the fact that the commodity specialist, carrying as he did a major share of the trade relations work of the agency, had little time or patience for processing paper. As a consequence, much of the delay in getting out orders occurred at this point in the process. When the adjustment procedure was revised in August I952, following organizational changes proposed for the field, responsibilities were assigned as follows:

The Price Actions Branch in each field office will make an analysis of each application and prepare an economic brief, setting forth the findings with respect to the application and recommending disposition. The attorney assigned to work on the action shall review the file to determine whether the proposed action is consistent with the regulation and otherwise meets legal standards established for the agency, and he shall draft any orders required to dispose of the application.

With this change, analytical work was concentrated at one point and the clearance process was considerably simplified. Commodity specialists, under the final arrangement, were available, of course, as consultants and advisers on trade practices.

Delays in processing price actions were of concern to all processing and supervisory officials at all times. Monthly reports showed an analysis of pending cases by length of time pending, which made it possible for each office to check up periodically on its performance. Some offices instituted weekly checkups on the status of pending cases in an effort to move them expeditiously. Thirty days were considered a reasonable time for an action to remain in the office. Reports coming in to the national office for the months of February, March, and April x952, showed that field offices were completing no more than one-third of the adjustment cases in process each month, and that there was a steady accretion in both receipts and backlog. In consequence, the Office of Price Operations made a survey to establish reasons for processing delays and to provide the basis for improving procedures. It was found that the median processing time for all cases was 47 days; individual offices varied widely from this point and some cases took over 200 days to process. Major causes for delay were found to rank in the order discussed below.

I. Handling requests for additional information. OPS found that many applications for adjustment could not be processed to completion without obtaining some additional information or verification from the applicant. Most of this additional information was requested by mail, and until it was received from the applicant, the case could not be completed. It was found in the survey that requests originated at all steps in the process, not just at the point of analysis by the commodity specialist, and, in some cases, applicants were being harassed by requests from several sources 
for different pieces of information. Field offices were cautioned to review applications more carefully, so as to make sure that all the information needed would be covered by one request. Furthermore, they were authorized to set time limits for reply, and to deny applications if information was not received by then, without prejudice to the right to reapply.

2. Shortage of personnel. Field offices indicated that insufficient personnel to handle the workload was a reason for delay in 22 per cent of the cases cited. Since OPS was undergoing a reduction in force by the time the survey was completed, there was no prospect of relief through recruiting. It was suggested that the price executive obtain better utilization where possible by reassigning staff from low priority areas. Furthermore, the reorganization plan which went to the field at this time was designed to make sure that the essential and irreducible work incident to processing price actions would be carried on without undue delay and inconvenience to the business public.

3. Delays in delegating, redelegating, or receiving instructions or obtaining clarifications of problems. Despite all the complaints made by field offices, and the undeniable fact that the national office was sometimes slow in making delegations and issuing operating instructions, only 7 per cent of the instances of actual delay in processing individual cases were attributable to this factor. Regional offices shared some of the blame through failure in some instances to make prompt redelegations to the district offices.

4. Preaudit. This was a supervisory and training device which regional offices, and the national office to a very limited extent, used to secure uniformity in processing results. In many instances, this meant an entire duplication of the work done by the office of original jurisdiction and a doubling of the processing time. The practice, ordered discontinued in August 1952, probably was pursued longer than was necessary, assuming proper corrective measures were taken by supervising offices.

5. Other reasons. The survey indicated that proper procedures were not always being followed to insure the timely cooperation of supporting staffs in the office of field counsel and in the office of accounting. These presented operating problems which required the intervention of the regional director.

Field offices subsequently demonstrated that, for the usual case, thirty days of processing time was not unreasonable. Regional and district directors took a hand in streamlining operations and in following the progress of overdue cases. Despite the continuation of heavy receipts, until the late fall of 1952 , field offices operated with minimum backlogs even though staff was severely curtailed after July, 1952.

OPS field offices processed $4 \mathrm{I}, 560$ docket actions of all types. While no precise measurements of impact were developed, it was generally conceded throughout the field that adjustment actions under CPR 34 (Services, I6 FED. REG. 4446 (I951)) and its supplementary regulations, and under GCPR, SR 39 (Contract Carriers, I6 FED. REG. 7 150 (195I)) required more processing time than any other type of action. In view of the preponderant number of these actions, it is probable that at least one third of the time devoted to price actions was spent on these services problems. 


\section{Exercise of Discretion by Field Offices}

Operating instructions dealing with processing individual price actions were generally prepared while a regulation or amendment was in process of clearance or shortly thereafter. This meant that actual operating experience, except as might be recalled from OPA experience, was not generally available to the drafters of field instructions. Problems and their solutions had to be anticipated, and presented in such a manner as to serve as guides to methods for handling actual fact situations.

In the development and clearance of operating instructions, two points of view came into conflict in the national office. Commodity division personnel, primarily responsible for preparation, tended to feel that explanation of the intent of the price action provision and general indication of results to be achieved were sufficient. Reviewing officials, particularly those on the Adjustment Coordination Committee, inclined toward a full exposition of the regulatory provision itself, and specificity in standards to be applied so that judgmental factors would be reduced to a minimum. It is probable that earlier instructions inclined toward the commodity view, while the Adjustment Committee, through its review function, caused later modification in approach. Field offices appear not to be in agreement as to which technique offered the better base for field processing. One regional economist wrote, for example: ${ }^{9}$

Operating instructions with regard to price actions were in the main adequate in almost all commodity and services fields, particularly when it is recognized that such operating instructions are supposed to represent general guide lines and a framework within which field offices are expected to exercise judgment and initiative.

On the opposite side, a regional director wrote: $:^{10}$

Reviewing adjustment standards in both the regulation and the Manual, the primary difficulties were that the standards were too frequently stated in too general terms, leaving too much leeway for interpretation. To assure proper coordination of processing of cases in all regions, these standards should have been specific and most carefully stated to allow for no possible interpretation other than the one intended by the writer. Clarification of the exact authority of the Manual should have been made to further avoid misinterpretations in the field.

An even clearer case of diametrically opposed views is evident in the quotations below:

National Office leadership and instruction was most effective in the services field under CPR 34 and the transportation field under SR 39 to GCPR. I aiso feel that the food price division did a very good job in instructing field offices with regard to the retail food regulations, but a much less effective job with regard to the two restaurant regulations. ${ }^{11}$

Generally speaking, the standards provided in the Manual were essential to proper process-

- Memorandum, Field Contributions to the OPS History Program, Franz Huber, Denver, to Raymond

C. Erb, Regional Executive, Mar. ro, r953.

${ }^{10}$ Letter, E. R. Thissen to Joseph H. Frechill, Mar. 13, 1953.

${ }^{11}$ Franz Huber, supra, note 9. 
ing of price actions, because the regulations did not, and could not, contain in any detail the guide for decisions by field offices. In many cases the Manual standards were clear and easy to follow. Those related to CPR II and CPR I34 [the Restaurant Regulations] are an example. In other cases, the standards were not sufficiently clear, and various interpretations were made of them. This was especially true of the Manual relating to SR 39. The outstanding case of a regulation whose Manual standards created problems was CPR 34. When these standards first reached the field they were incomplete, in places inconsistent, and in some instances prescribed action that did not appear to us to be justified. It required several months to discover all the problems, report them to Washington, and get approval of the National Office to proposed solutions. The related Manual sections were never revised as they should have been. While some differences of philosophy on the part of our processing personnel were bound to be reflected in different approaches and interpretations in the case of many regulations, this situation was aggravated in the cases arising under CPR $34{ }^{12}$

A view to which most field offices would probably have subscribed is that instructions should be made as specific as possible, but that field offices should be given some discretion in dealing with new and unusual problems or where prescribed standards result in obvious inequities. The Kansas City Director stated this position, as follows: $:^{13}$

We realize that the National Office was desirous of achieving uniformity of administration as between the different Regions and Districts. It is our view that this is to be achieved, not by a requirement that all problems not precisely covered by regulation, Manual instruction, or interpretation, be referred to the National Office for decision, but rather by training field office personnel in the agency's over-all purposes, policies and standards and then exercising a close check on measures, such as personnel changes or pre-audit requirements, where necessary. Field offices should be required to make a memorandum report of all such problem cases and how they were solved. The National Office should reverse particular field office decisions only in extreme cases, but should issue instructions for future guidance or even formulate new rules if the problem may be expected to be fairly widespread. Any office which habitually abuses its discretion and fails to conform to overall policies in its particular decisions, should be disciplined by requiring pre-audits of decisions and/or making changes in key personnel.

Our objection to withholding discretion from field offices is that it simply doesn't work. Field offices that will conform to the rules to the best of their ability, even though they may not agree with them, are the offices that are most to be trusted with discretionary authority. Those offices that can't be entrusted with discretionary authority will presume to exercise it anyway no matter how precise the rules. The limits to field office discretion should, of course, be clearly defined.

Early instructions on processing adjustments permitted, at least by implication, some departure along these lines, from strict application of instructions, but in later revisions the latitude given the field price executives was removed. Under the organizational arrangement of field offices, there was no way that the field price executive could make his judgment prevail. The prerogative was dropped in an effort to reduce causes of friction between price people and other clearing officers, particularly field counsel.

${ }^{12}$ Letter, James G. Lyons, Regional Director, New York, to Joseph H. Freehill, Mar. 12, 1953.

${ }^{13}$ Letter, M. A. Brooks to Joscph H. Frechill, March I3, 1953. 


\section{IMPROVING Regulations}

Every field office was constantly on the watch for problems which were inadequately treated in the regulations or which needed to be corrected through the issuance of a new regulation or an amendment to an old one. These were brought to the attention of the national office through regular reports, requests for interpretation, special correspondence, visits of field personnel to the national office, field conferences, and enforcement cases.

Price specialists and field counsel were the sources of most recommendations for regulatory changes or improvements. In the case of the price specialist, a normal part of his duties consisted of evaluating regulations and presenting his views on modification: $:^{14}$

Every commodity specialist should keep himself informed of the climate in which the regulations pertaining to his specialities are operating. He should be able to identify problems encountered by the industry, ascertain causes, assess the general or local nature of the price stabilization program. He should measure the effect of existing regulatory techniques in terms of the program objectives and recommend improvements to attain these objectives. At all times, he should strive to be familiar with the plans for his specialty, as communicated through regular program reports from the national office and other channels available to him, and he should make a critical evaluation of these plans in terms of administrative feasibility, acceptance by the industry and the public in his area, and impact on the economic situation in his region or district. He will use both regular and special reporting devices to make available to his regional or district price executive and to the national office his information and views.

In carrying out the interpretative functions, counsel was given the following warning: ${ }^{15}$

In interpreting regulations, orders or allocations issued by the Director of OPS relating to price controls, it must be borne in mind that an interpretation is not an amendment and should neither add to nor detract from the substantive meaning of the regulation. Where a particular result is desired but cannot be justified within the framework of the regulation, such result must be obtained by amendment. In short, regulations may not be amended by interpretation.

Both of these groups of field officers took their responsibilities seriously, and dutifully and repeatedly called defects to the attention of the national office, frequently making complete recommendations for overcoming them.

Regular narrative progress reports of field offices were normally used to transmit recommendations. Field offices quite frequently felt that no action on the part of the national office meant that their reports went unread or that their suggestions were discarded. This would seem to be an unwarranted conclusion. Wide distribution was given to the reports, and where particular problems cited seemed to

\footnotetext{
14 Price Staff Instruction No. 14, "Activity of Field Price Offices," May 22, 195I, also Butget Operating Plan for Quarter Ending September 30, 1951.

${ }^{25}$ OPS Manual Pt. 5, c. 4.
} 
demand an individual response, national office divisions or branches did their best, in view of the many pressing problems coming over their desks each day, to advise the field correspondent. More frequently, the national office used its own narrative report as a means of dealing with problems raised by the field and from other sources.

After continual prodding from the field price office, most commodity divisions eventually installed a point-by-point reply to field offices which represented a roundup of all problems raised and the views of the national office as to what could be achieved. Many of the problems obviously could not be dealt with on the basis proposed by field offices. The fact that a suggestion was made by a field office did not necessarily clothe it with merit. Field offices were, sometimes, loath to accept national office reasons for not acting in a proposed manner, and the consequent repetition of such proposals helped to build up a feeling of frustration on the part of the field offices and diffidence on the part of the national office.

Another method of securing field suggestions was through the Regional Small Business Representative who submitted periodic reports to the Assistant to the Director for Small Business, covering problems faced by these sellers and proposals for handling them. Quite often, these reports covered materials already presented through other communications. They did, however, serve to focus attention, and perhaps to get faster action than through regular operating channels.

\section{Evaluating Compliance}

During the early ESA regime, the Office of Field Operations had specifically recommended the establishment of an Office of Program Analysis and Review for each regional office which would constantly evaluate the progress of the field in reaching program objectives, so that the agency, as a whole, would have a sound informational base for measuring the effect of its regulations in achieving stabilization goals. This recommendation came directly out of observations of a deficiency in OPS which materially reduced the ability of the central office of that agency to deal effectively with major program problems. Without the mechanics for evaluating results and taking corrective measures on a national basis, it operated on the principle of the squeaking wheel. As in many other respects, OPS, in copying its predecessor, made no improvement over that agency's methods of securing basic program facts.

OPS issued regulations in order to carry out its part in the stabilization program. It assumed that compliance with its regulations would produce the desired effect. It further assumed that the overwhelming majority of sellers ${ }^{16}$ would comply with the regulations. Lastly, it assumed that price movements and other indexes to economic stability reflected in some measure the effect of compliance with its regu-

${ }^{10}$ The agency used 90 per cent as a basis for enforcement policy. 
lations. It concluded, therefore, that its regulations did, in fact, contribute to the stabilization program. ${ }^{17}$

With its faith in its own effort thus established, the agency did not undertake an administrative examination of its basic premises. There were many reasons why this could not be done by OPS. Among them were (I) preoccupation of top policy staff with day-to-day regulatory problems; (2) lack of a general research program for the agency; (3) preoccupation of commodity staff in the national office with regulatory development; and (4) the identification of responsibility for compliance with enforcement effort.

In short, the agency made little attempt to measure what was actually accomplished through its regulations against what was intended. Here the agency presented a vulnerable front to its critics, for it denied itself the opportunity to keep in touch with reality and opened the door to charges of ineffectiveness and maladministration. These charges served to divert attention from the basic objection to the program which many of its critics held, namely, that they were opposed in principle, and in practice, to price control.

The agency probably could have sustained a contention of effectiveness in its regulatory program on the ground that the great volume of commodities were sold and services were supplied at prices at or below legal ceilings. But this did not satisfy requirements for responsible administration. There were notable instances of regulations where non-compliance was known to be widespread among the mass of sellers, mainly small sellers, subject to them. The enforcement staff, developed to deal with the occasional willful violator, could not bring about compliance through coercion or appeal to conscience in these aggravated situations. In allowing these situations to continue, the agency ran a grave risk of encouraging disrespect for governmental authority as well as of discrediting the valuable emergency method of dealing with threats to economic stability through direct controls.

There were two ways open to OPS to deal, through its regulations, with the problem of non-compliance. One was to retire from the field..$^{18}$ The other was to modify regulations so that compliance could be more readily secured. The substitution of CPR I34 (a regulation for restaurants based on a freeze of menu prices)

\footnotetext{
${ }^{17}$ For a good example of this kind of reasoning, see Michael V. DiSalle, "Report to Roger L. Putnam, Administrator, Economic Stabilization Agency," Dec. 9, I952. He began his report as follows:

"There seems to be a general unanimity of opinion that today the nation is experiencing a period of economic stability. The Joint Committee on Defense Production states in its most recent report: 'In the 12 months which have elapsed since the First Annual Report of the Joint Committce on Defense Production, the operation of our economy has been quite stable. This stability is revealed by a close study of commodity prices at the present time as compared to a year ago.'

"That this situation might have been achieved without the imposition of direct controls has been debated, but we know as a certainty that it has been achieved with the use of direct controls and that our production and productive capacity has increased to high levels not long ago deemed unattainable."

${ }^{18}$ For OPS, this avenue of retreat was through selective suspension or exemption. The proposed small business exemption program is illustrative of a general method by which the problem of noncompliance, especially at retail levels where it was pronounced, could have been considerably minimized. Soft markets and the competition of larger stores may have reduced the extent of non-compliance with ceiling prices, even though non-compliance with formal requirements was admittedly widespread.
} 
(I7 FED. REG. $275^{\circ}$ (1952)) for CPR II (a regulation based on the difficult requirement of maintenance of a base period food cost ratio) (I6 FED. Reg. 239I (I95I)) was prompted in the main by the problem of the small restauranteur who could not comply with the requirements of CPR II. To a certain extent, the vast number of supplementary regulations to the GCPR and to other general regulations were prompted by similar considerations. It is probably not too severe an indictment of the agency to say that it did not go far enough in either of these directions to reduce non-compliance to the minimum consistent with sound administration. Without a firm body of facts on these problems, which field offices could have assisted in developing, the agency had difficulty both in defending its ground and in establishing lines for strategic retreat.

\section{A. Compliance Drives}

Offering no guidance on how to deal with the pervading compliance problem, the national office let the field offices develop their own techniques and methods. Field offices, after they had exhausted the educational approach as a method of obtaining voluntary compliance, turned to the compliance drive as the most efficacious method available to them. Cooperation of Enforcement was vital to this effort, and in most instances was secured. The Boston Office reported its method of conducting surveys as follows: $:^{19}$

... we learned that there was no alternative method as suitable to the purpose as "house to house" physical check of compliance. Certainly the method was more expensive than the use and evaluation of questionnaires and paper-work surveys, but it had a value far above the collection of factual data relative to compliance. The physical presence of OPS was made known to innumerable establishments and the mass of regulations "was made flesh" by the visitations of our personnel to the place of trade. In this region we used compliance teams who at one and the same time spread the gospel and evaluated its results. It did much to strengthen good trade relations and to create respect for the law. The major stumbling block in the way of obtaining good compliance was the absence of a standing operating procedure in this field which should have been issued with the publication of each regulation and amendment. It is regrettable that "know-how" in these respects had to be developed in the crucibles of day-to-day experience instead of being spelled-out by the authors of the regulations.

\section{A variation of this technique was used in Philadelphia: ${ }^{20}$}

... the most effective Complaince Program we had in operation was one which we used on Food, Restaurant and Service establishments. This involved sending a task force into a selected area to make a cross-section check. Violators were then given notice to appear at a pre-arranged clinic with this task force, at which time they were received in a very friendly fashion, the regulations again explained to them and they were again instructed as to the necessity of compliance with the regulations in question. Subsequent checkups were then made of the very same establishments and those found to be still in violation were then referred to the Enforcement Division for action.

${ }^{10}$ Letter, Joseph M. McDonough to Joseph H. Freehill, Mar. Io, 1953.

${ }^{20}$ Letter, Joseph J. McBryan, Regional Director, to Joseph H. Freehill, Mar. 12, 1953. 
Nearly every regional office developed a similar technique, using Price and Enforcement staffs or other personnel to the extent that they could be spared from regular duties. While a a total statistical picture of this activity is not available, some indication of the number of contacts made through compliance drives in which Enforcement personnel participated may be obtained from the table below, covering this work for the most active period of the agency.

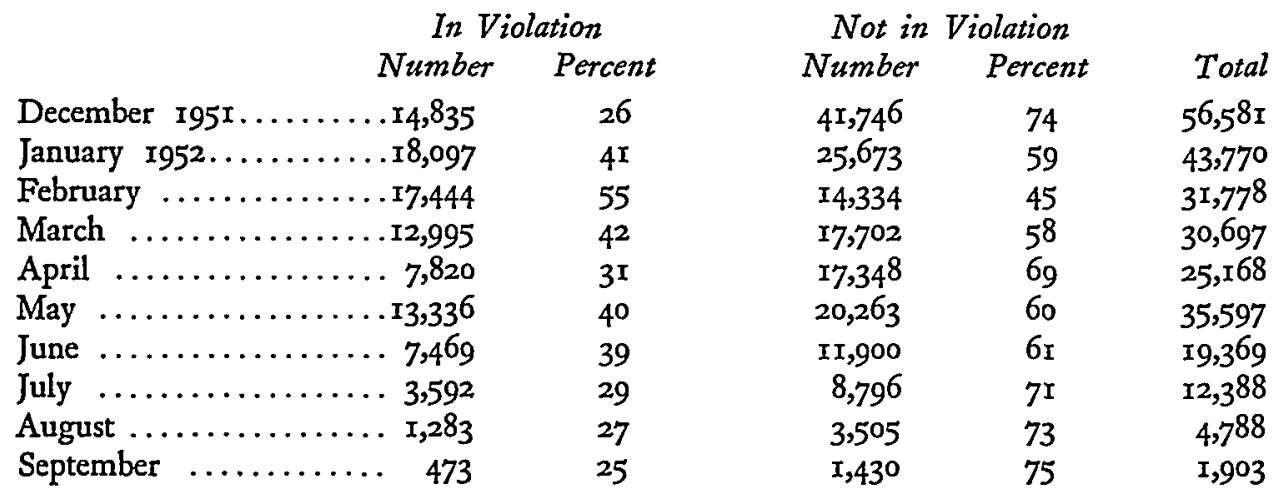

\section{Identifying and Punishing Vyolators}

A staff memorandum issued by Mr. DiSalle in August I95r called attention to a problem which faced every employee in OPS who had official dealings with businessmen subject to OPS regulations. His memorandum read, in part, as follows:

My attention has been called to a number of instances in which complaints of or other information relating to possible violations have been received by members of the Price Division and other OPS personnel but have not been forwarded to Enforcement. In a number of instances, also, members of the Price Division have undertaken to dispose of violations which have come to their attention, without reference to or consultation with Enforcement personnel.

Your attention is again called to the fact that the Director of Enforcement in the National Office, and within their respective jurisdictions, the District Enforcement Directors in the District Offices are charged with exclusive responsibility for the handling of all complaints, and conduct of all investigations relating to possible violations and the disposition of all such cases. No one other than an authorized member of the Office of Enforcement is empowered to compel the production or inspection of records or to require the giving of testimony. And no other than an authorized member of the Office of Enforcement is empowered to settle, adjust, waive or otherwise dispose of any kind of violation or complaint, regardless of the amount or degree of violation actually or apparently involved. Whether a violation is a so-called "minor" or "insignificant" or "innocent" or "technical" one is usually a matter of definition which should be resolved only by an authorized Enforcement representative; it should be kept in mind that even such a violation may be only a symptom of a more general condition of non-compliance by the seller which should be inquired into and handled only by Enforcement personnel.

The fact that it was necessary to issue such a memorandum provides an effective 
illustration of the difficulties the agency experienced in getting its operating gears to mesh. While there was some complaint, especially from price people, that the terms were so categorical as to make it impossible for an effective trade relations program to be carried on, most employees realized that it presented a sound approach to a delicate situation. Furthermore, it provided an opportunity, of which most offices took advantage, for all segments of the agency to begin to work more closely with each other.

It is obvious that the purpose of referring these cases to Enforcement was not so that treble damage or criminal action would be taken in every case. Rather, it was to obtain compliance wherever possible, employing sanctions judiciously where they would have the most effect in deterring future violations. This is not to say that violations were overlooked or ignored, but Enforcement did not regard itself, primarily, as either a collection agent for the United States Treasury or as a sleuth for the Department of Justice. Both of these roles were important ones which could be assumed when circumstances required, but the more usual aspect of enforcement work was less spectacular.

The question naturally arises as to how cases came to Enforcement. As discussed in the preceding section, compliance surveys, whether conducted by Price or Enforcement, produced the majority of cases. Individual complaints by business establishments or consumers were another important source. A third source was from records of price filings and trade contacts, through clinics, inquiries, and interviews. Although the agency never developed general operating procedures governing the transfer of information from price records to enforcement records, operating instructions on numerous price action provisions required consultation with or notification of enforcement when delinquencies appeared.

For the Enforcement staff, limited as it was in investigative personnel particularly, the problem of dealing with retail violations was insurmountable. Since the agency did not, as a general rule, establish dollars-and-cents ceilings for retailers, most ceiling prices had to be determined by the retailers themselves from base period records of some kind or current invoices. Adherence to record-keeping requirements, therefore, was of great importance to the maintenance of price control. For many retailers, particularly the small ones, these requirements not only were burdensome but represented refinements in their business practices which they were, in many instances, not equipped to carry out, without instruction from OPS personnel. The more formidable enforcement sanctions obviously were not appropriate for these sellers unless their failure to comply resulted from flagrant disregard or defiance of governmental authority.

The compliance conference was found to be, in general, the most effective means for dealing with retail violators. This was the sanction generally used by enforcement if price clinics or other methods failed to bring about compliance. In OPA the compliance conference or hearing was used extensively by the War Price and Rationing Boards to bring retailers into compliance. There was no such organiza- 
tional level in OPS, and in consequence the main burden fell on Enforcement.

Among the obstacles to speedy enforcement action, especially during the first year of OPS, were the limitations on the exercise of sanctions by District Enforcement Directors. Because of the working relationships between the Office of Enforcement and the Department of Justice, the District Enforcement Directors at the outset were required to submit all recommendations for litigation to the national office for review and referral to the Department of Justice for subsequent action. It was not until December I95I that they were authorized to negotiate compromise settlements of government damage claims for overcharges of $\$ r, 000$ or less, a delegation which could have been made earlier since this sanction was never limited by the agreement with the Department of Justice. This limitation was raised in August 1952, to $\$ 15,000$ or less. Finally, in September I952, further clarification of relations with Justice permitted the delegation of authority to the District Enforcement Directors to institute, through the United States Attorneys, cases involving injunctive actions and all treble damage actions that did not exceed $\$ 50,000$.

The problem of recruiting, developing, and training a sufficiently large and competent investigative staff to carry on the enforcement work of the agency was one which plagued the field from the beginning. Given the compliance situation which OPS faced and the attitudes of both business and the public toward the stabilization program, the problems of determining need and making most effective utilization of staff were made doubly difficult. Workload of the enforcement staff, therefore, was not so much related to work to be done as it was to available resources with which to undertake it. The investigators were the mainstay of the field enforcement staff, and a usual work measurement for an office was the case load per investigator. In June 1952 , there were $I, 384$ investigators out of a total district enforcement staff of 2,657 , or 52 per cent. While the average case load per investigator was 30.6, individual regional averages varied widely from this point, ranging from 64. $\mathrm{x}$ in Boston, followed by $5^{\mathrm{r} .9}$ in San Francisco, to 20 in Atlanta and I8.8 in Seattle. For this same month, the pending case load, as broken down by commodity areas, showed Consumer Goods (including Services), $5^{\mathrm{I}}$ per cent; Food and Restaurants, $3^{6}$ per cent; Industrial Materials and Manufactured Goods, I3 per cent.

Even in carrying out the function for which it had prime responsibility, that of punishing violators, Enforcement could not operate with the exclusiveness assumed in its organizational arrangement. It had to rely on field accountants to make such audits as were required in the conduct of its investigations and it had to rely on the Office of the Chief Counsel and its field counterparts for interpretations and opinions. On the latter problem, the Director of Enforcement instructed his staff, as follows: $:^{21}$

It is vitally important that all Enforcement Legal personnel and that all other Enforcement personnel working pursuant to the direction of and under the supervision of Enforcement Legal personnel be reminded that the Chief Counsel and his delegates have

${ }^{21}$ Instructional Memorandum No. 85, Aug. 10, 1951. 
exclusive authority to render official interpretations; and, that all such personnel be admonished against rendering interpretations, under any circumstances.

No personnel identified with the Office of Enforcement on the staff of the Washington Office, the Regional Office, or the District Office levels shall, in any event or under any circumstances, render an interpretation or opinion, oral or written, with or without reservations, qualifications, or limitations. There will be no exceptions made to this absolute prohibition.

\section{VII}

\section{Compliance Actions}

While the actions of the Enforcement staff by no means indicate the wide range of field effort toward securing compliance with regulations, the results in this area are perhaps the most tangible evidence available of administrative determination to make the price regulations effective.

The direct accomplishments of Enforcement through the exercise of authority to negotiate settlement and through the instigation of civil and criminal actions were summarized for the agency as follows: ${ }^{22}$

In compromising approximately 4,500 cases, Enforcement recovered more than $\$ 5,000,000$ for the Government. We were responsible for effecting direct restitution to overcharged consumers in a total amount of nearly one-half million dollars. We have referred to Justice and now have pending in court civil suits through which $\$ 12,000,000$ in single damages alone may be recovered. Out of 1,500 civil damage suits filed, we have lost only I7. We caused 2,000 injunctive and 200 criminal cases to be filed. Through these actions and other forms of Enforcement activity, we have undoubtedly saved the consuming public many millions of dollars and have protected the government, as a purchaser, from uncounted price increases in connection with defense production expenditures.

${ }^{22}$ Memorandum, Enforcement, Harry N. Stein to Joseph H. Freehill, June II, I953. 